\title{
Reasons for Culling in Relation to Longevity and Lifetime Efficiency of Landrace and Large White Sows in a Nucleus Breeding Farm in the Philippines
}

\author{
O. L. Bondoc ${ }^{\mathrm{a}, *} \&$ J. F. Isubol ${ }^{\mathrm{b}}$ \\ anstitute of Animal Science, College of Agriculture and Food Science, University of the Philippines Los Baños, \\ College, Laguna 4031, Philippines \\ ' International Farms Corporation (INFARMCO), Brgy. San Isidro, \\ Cabuyao City, Laguna 4025, Philippines \\ *Corresponding author: olbondoc@up.edu.ph \\ (Received 12-05-2021; Revised 16-07-2021; Accepted 04-08-2021)
}

\begin{abstract}
Information on the reasons for sow removal is limited and often unreported for nucleus breeding farms. This study analyzed the distribution of culling type (planned vs. unplanned) and culling reasons in relation to longevity - parity at culling (PAC) and productive herd life (PHL), and lifetime efficiency - lifetime pigs born alive (LPBA) and total pigs weaned (TPW) using data recorded from 2017 to 2019 by a local nucleus breeding farm. The study revealed a considerable amount of unplanned removal (84.1\%) compared to planned culls, which is due to old age $(\mathbf{1 1 . 4 \% )}$ and poor farrowing performance $(\mathbf{4 . 6 \% )}$ ). The most common reasons for unplanned sow removal were reproductive failures $(26.2 \%)$ and health disorders $(23.4 \%)$, followed by physical defects $(15.3 \%)$, leg/foot problems (10.8\%), and mortality (8.5\%). A high proportion $(22.1 \%)$ of sows was culled at their first parity. The proportion of culled sows decreased up to parity 4, especially for unplanned sow removals due to reproductive failures, leg/foot problems, and mortality. Unplanned culling corresponded to lower PAC (3.8), PHL (459 days), LPBA (14.1 pigs/year), and TPW (12.4 pigs/year). Average PAC and PHL were significantly higher $(\mathrm{p}<0.05)$ for Large White sows $(\mathrm{PAC}=5.2 ; \mathrm{PHL}=$ 696 days) than Landrace sows (PAC $=4.6 ; \mathrm{PHL}=588$ days). However, the LPBA and TPW were not significantly different between breeds. Information about sow removal could be used to develop management strategies to avoid unplanned culling in purebred sows and extend their productive life.
\end{abstract}

Keywords: sow culling; longevity; lifetime efficiency

\section{INTRODUCTION}

In commercial swine operations, sow culling rates average near $50 \%$. Sows are removed from the breeding herd for various reasons and may cause many breeding females to leave the farm before they have reached their third parity, an age when most females recover their investment costs (Mote et al., 2009). To maintain consistent production, a culling policy based on the parity profile of the breeding animals is required in a swine farm to avoid old sows that are retained too long in the herd and young sows that are removed too early from the herd (de Jong et al., 2014). However, unplanned removal of sows may decrease the production efficiency of commercial herds due to huge fluctuations in the number of replacement gilts and reduce the lifetime production of sows (Sasaki \& Koketsu, 2012).

Lifetime production of sows can be measured as lifetime pigs born alive (LPBA). As a measure of prolificacy, it is related to parity at culling (PAC) or longevity (Engblom et al., 2007). Sows with more pigs born alive had a lower risk of being culled (Hoge \& Bates, 2011).
However, PAC does not directly indicate sow fertility and lifetime efficiency since parity at culling ignores nonproductive days and fertility that is accumulated by prolonged weaning-to-conception and culling intervals. The annualized LPBA is thus a better measurement of lifetime efficiency as it is relatively more related to nonproductive days per parity compared with litter size at birth per parity (Sasaki \& Koketsu, 2008).

The sow lifetime efficiency depends on culling and mortality rates and varies with culling reasons (Sasaki \& Koketsu, 2011). Culling reasons may vary over time, among countries, herds, and parities. The reasons for culling are influenced by many factors such as sow genotype, housing conditions, and management policies (De Jong et al., 2014). Hence, the findings based on decades-old studies involving sows far less productive than today are not always comparable with other countries in the tropics such as the Philippines, because of major differences in management, feeding, genetics, climate, and housing conditions.

While the reasons for sow culling are reported mostly to improve the production efficiency of com- 
mercial herds abroad (e.g., Hoge \& Bates, 2011; Sasaki \& Koketsu, 2011; Wang et al., 2019), the reasons for removal of purebred sows and their lifetime efficiency in a local nucleus breeding farm are not known. In this regard, the objective of this study is to analyze the distribution of culling type (planned and unplanned) and culling reasons for Landrace and Large White sows in a local nucleus breeding farm. The study also aims to determine the longevity and lifetime efficiency of culled sows in relation to different culling types and culling reasons.

\section{MATERIALS AND METHODS}

\section{Animal Care}

The Animal Care and Use Committee approval was not obtained for this study because the data were obtained from an existing database of a privately-owned swine nucleus breeding farm.

\section{Data Collection, Definitions, and Categories}

Culling data and lifetime records were obtained from 791 purebred sows (466 Landrace and 325 Large White) that were culled within a 3-years period (2017-2019) at the International Farm Corporation (INFARMCO) swine breeding farm in Barangay San Isidro, Cabuyao City, Laguna.

Sows were equally managed while fulfilling all welfare requirements and were kept in individual parturition pens inside tunnel-ventilated buildings about 2 weeks before farrowing until weaning. Sows were fed manually twice a day with commercial gestation ration until farrowing (i.e., $3.0-3.5 \mathrm{~kg} / \mathrm{sow} /$ day) and lactation ration after farrowing until weaning (i.e., $4.0-6.0 \mathrm{~kg} /$ sow/day). Detection of estrus in sows using boar contact was performed twice a day after weaning. All breeding females were artificially inseminated at $12 \mathrm{~h}$ and $36 \mathrm{~h}$ after first detecting estrus, and a real-time ultrasound was used to detect pregnancy 23 to $28 \mathrm{~d}$ after insemination.

The data set contained information about sow removal (date of culling, reasons for culling) and individual performance data (date of first farrowing, the total number of piglets born alive, total pigs weaned). The culling rate for the period under study was approximately $45 \%-50 \%$.

Sow longevity was measured in terms of parity at culling and productive herd life. Parity at culling (PAC), also called lifespan, is the number of parities a sow has accumulated before culling (Engblom et al., 2007; Hoge \& Bates, 2011; Sasaki \& Koketsu, 2011; Sobczyńska et al., 2014; Zhao et al., 2015; Wang et al., 2019). Productive herd life (PHL) refers to the number of days from the date of first farrowing to the date of culling or mortality (Hoge \& Bates, 2011; Sobczyńska et al., 2014).

Sow lifetime efficiency in terms of annualized lifetime pigs born alive (LPBA) and total pigs weaned (TPW) is defined as the sum of pigs born alive (or pigs weaned) in a lifetime (i.e., from first farrowing to the last farrowing) divided by the sow life days and multiplied by 365 days. Lifetime productivity or efficiency is also called lifetime prolificacy by Sasaki \& Koketsu (2008), Hoge \& Bates (2011), Sasaki \& Koketsu (2011), Sobczyńska et al. (2014), and Wang et al. (2019).

The components of culling type and culling reason are shown in Table 1. Culling type was categorized into planned and unplanned sow removal. The planned sow removals were due to poor farrowing performance and old age. Sows with poor farrowing performance are culled following the selection criteria used by the farm management for purebred sows. Sows over parity 5 are culled primarily because of old age and lowered productivity. However, older sows with aboveaverage productive sows were also used to produce $\mathrm{F}_{1}$ Landrace $\times$ Large White crossbred gilts. These sows are typically culled after the $10^{\text {th }}$ parity. The reasons for the unplanned removal of sows were categorized into reproductive failures, health disorders, physical defects, leg/foot problems, and mortality (modified from Mote et al., 2009 and Sasaki \& Koketsu, 2012).

\section{Statistical Analysis}

All statistical analyses were performed in SAS software version 9.2 (SAS Inst. Inc. Cary, NC, USA). A chi-square test (PROC FREQ) was used to examine the distribution of culled sows by breed, culling type, and culling reason at different culling parities. The Pearson product-moment correlation coefficients (PROC CORR) were determined among measures of longevity (PAC and PHL) and lifetime efficiency (LPBA and TPW).

The sow longevity and lifetime efficiency measures were analyzed using the general least squares procedures for unbalanced data sets (PROC GLM). The mathematical model was:

$\mathrm{y}_{i j k l}=\mu+$ Breed $_{i}+$ CType $_{j}+$ CReason $_{k}\left(\right.$ CType $\left._{j}\right)+($ Breed $x$ CType $)_{i j}+\mathrm{e}_{i j k l}$

where $\mathrm{y}_{i j k l}$ is parity at culling, productive herd life, lifetime pigs born alive, and total pigs weaned, $\mu$ is the overall mean, Breed ${ }_{i}$ is the fixed effect of the $i^{\text {th }}$ breed of sows (i.e., Landrace and Large White), CType ${ }_{j}$ is the fixed effect of the $j^{\text {th }}$ culling type (i.e., planned and unplanned), CReason ${ }_{k}\left(\right.$ CType $\left._{j}\right)$ is the effect of the $\mathrm{k}^{\text {th }}$ culling reason within the $j^{\text {th }}$ culling type, (Breed $\times$ CType $)_{i j}$ is the interaction effect between the $i^{\text {th }}$ breed and $j^{\text {th }}$ culling type, and $\mathrm{e}_{i j k l}$ is the error term assumed to be normally distributed with the variance of errors as constant across observations. Statistical significance was set at $\mathrm{p}$-value $<0.05$. The least-square means (and standard error) for each dependent variable were used to compare breeds, culling types, and culling reasons.

\section{RESULTS}

\section{Distribution of Culling Type and Culling Reasons at Different Parities}

The reasons for planned culling were due to old age $(11.4 \%)$ and poor farrowing performance $(4.6 \%)$, see Table 2. The low proportion of sow culling due to poor farrowing performance was mainly attributed to dystocia $(1.9 \%)$ and stillbirths or mummified fetus $(1.1 \%)$. The 
Table 1. Classification of culling type and culling reasons

\begin{tabular}{|c|c|c|}
\hline Culling type & Culling reason & Components \\
\hline \multirow[t]{6}{*}{$\begin{array}{l}\text { Planned sow } \\
\text { removal }\end{array}$} & \multirow[t]{5}{*}{ Poor farrowing performance } & $\begin{array}{l}\text { Dystocia (difficulty in giving birth, prolonged farrowing, retained placenta or } \\
\text { piglets) }\end{array}$ \\
\hline & & Low litter size at birth (below 7 piglets born alive) \\
\hline & & Stillbirths/ mummified fetus (including sows with no weaned piglets) \\
\hline & & Early farrowing (more than 14 days before expected date of farrowing) \\
\hline & & Poor milker (little or no milk produced) \\
\hline & Old age & Parity greater than 5 \\
\hline \multirow{14}{*}{$\begin{array}{l}\text { Unplanned sow } \\
\text { removal }\end{array}$} & \multirow[t]{5}{*}{ Reproductive failures } & No pregnancy \\
\hline & & Abortion \\
\hline & & Rebred twice (failure to conceive after being rebred at least twice) \\
\hline & & No heat cycle (no signs of heat observed) \\
\hline & & $\begin{array}{l}\text { Long dry period (more than } 45 \text { days dry period for first parity sows and more } \\
\text { than } 30 \text { days dry period for sows with more than } 2 \text { parities) }\end{array}$ \\
\hline & \multirow[t]{4}{*}{ Health disorders } & Vaginal infections (discharge) after breeding \\
\hline & & Respiratory problems (pneumonia and asthma) \\
\hline & & $\begin{array}{l}\text { Poor appetite (low feed intake leading to significant weight loss and poor body } \\
\text { condition) }\end{array}$ \\
\hline & & Fever \\
\hline & \multirow[t]{3}{*}{ Physical defects } & Downer sow syndrome (cannot stand and eat) \\
\hline & & $\begin{array}{l}\text { Defective (combination of two or more of defects such as inflamed tail, small } \\
\text { teats, damaged or cut teats, tumor or abscess growths, umbilical hernia, damaged } \\
\text { vulva, thin and weak sows, with black spot/blemish) }\end{array}$ \\
\hline & & Rectal prolapse \\
\hline & Leg/foot problems & Lameness and locomotion problems (weak legs, splayed legs, flat-footed) \\
\hline & Mortality & Sudden deaths, heat stroke \\
\hline
\end{tabular}

rate of planned culling was higher in Large White sows (9.4\%) than in Landrace sows $(6.6 \%)$.

The rate of unplanned sow culling was $84.1 \%$ in total culls (Table 2). The most frequent reasons for unplanned sow removal were reproductive failures $(26.2 \%)$ and health disorders $(23.4 \%)$, followed by physical defects (15.3\%), leg/foot problems (10.8\%), and mortality $(8.5 \%)$. Reproductive failures in the nucleus breeding farm were mainly due to "no pregnancy" or failure to conceive $(10.8 \%)$ and abortion (7.3\%). Health disorders were mainly attributed to vaginal infections in newly bred sows $(12.4 \%)$, poor appetite $(5.3 \%)$, and respiratory problems $(4.9 \%)$. Physical defects were mainly attributed to "defective" (7.3\%) and downer sow syndrome (7.2\%). Leg/foot problems were mainly attributed to weak legs $(5.8 \%)$ and foot rot $(3.9 \%)$.

The percentages of culling type and culling reasons throughout the sow's productive life (i.e., different culling parities) are shown in Table 3. About half (50.6\%) of all sows culled in the nucleus breeding farm was made in the first 3 parities (i.e., $22.1 \%, 14.4 \%$, and $14.0 \%$ in parity 1,2 , and 3, respectively). During this period, most sow removals were unplanned $(47.9 \%)$, mainly due to reproductive failures $(17.3 \%)$, health disorders $(13.8 \%)$, and physical defects $(8.5 \%)$. The removal of sows due to reproduction failures, leg/foot problems, and mortality declined steadily until parity 4 . On the other hand, most sows removed after parity 6 to $10(31.4 \%)$ were due to old age $(11.4 \%)$, health disorders $(5.3 \%)$, and leg/foot problems $(4.7 \%)$.

The planned removal of purebred sows due to old age was observed only after the fifth parity. Planned culling reasons due to poor farrowing performance was only $2.6 \%$ until parity 3 .

\section{Sow Longevity and Lifetime Efficiency in Relation to Culling Type and Culling Reasons}

Parity at culling (PAC) was highly correlated with productive herd life (PHL), i.e., $r=0.98$. Large White sows were culled at higher parities and had higher productive herd life than Landrace sows by +0.6 parity and +108 days, respectively (Table 4). Planned sow removal, as expected, corresponded to sows with significantly higher PAC and PHL than the unplanned sow removals by +2.1 parities and +367 days, respectively. Average PAC and PHL were highest for planned culling due to old age at 8.6 parities and 1268 days, respectively. The highest PAC (4.8 parities) and PHL (634 days) were observed for unplanned sow removals due to leg/foot problems. The lowest PAC (3.3 parities) and PHL (370 days) were found for sows removed due to reproductive failures. Averages PAC and PHL were significantly higher in the unplanned sow removal of Large White sows (4.4 parities and 553 days) than in Landrace sows (3.2 parities and 364 days).

The annualized LPBA and TPW of all purebred sows were 14.3 pigs/year and 12.6 pigs/year, respectively. LBPA was highly correlated with TPW ( $\mathrm{r}=0.98)$. Lifetime efficiency in terms of LPBA and TPW was not significantly different $(\mathrm{p}>0.05)$ between Landrace and Large White sows (Table 4). Planned sow removal was made for sows with significantly higher LPBA (16.5 vs. 14.1 pigs/year) and TPW (13.9 vs. 12.4 pigs/year) than 
Table 2. Distribution of Landrace and Large White sows based on culling type and culling reasons

\begin{tabular}{|c|c|c|c|c|c|c|}
\hline \multirow{2}{*}{ Culling reason } & \multicolumn{2}{|c|}{ Landrace } & \multicolumn{2}{|c|}{ Large White } & \multicolumn{2}{|c|}{ Landrace + Large White } \\
\hline & $\mathrm{n}$ & $\%$ & $\mathrm{n}$ & $\%$ & $\mathrm{n}$ & $\%$ \\
\hline \multicolumn{7}{|l|}{ Planned sow removal } \\
\hline 1. Old age & 36 & 4.55 & 54 & 6.83 & 90 & 11.38 \\
\hline 2. Poor farrowing performance & 16 & 2.02 & 20 & 2.53 & 36 & 4.55 \\
\hline Dystocia & 10 & 1.26 & 5 & 0.63 & 15 & 1.90 \\
\hline Stillbirths/mummified fetus & 1 & 0.13 & 8 & 1.01 & 9 & 1.14 \\
\hline Low litter size at birth & 4 & 0.51 & 2 & 0.25 & 6 & 0.76 \\
\hline Early farrowing & 0 & 0.00 & 4 & 0.51 & 4 & 0.51 \\
\hline Poor milker & 1 & 0.13 & 1 & 0.13 & 2 & 0.25 \\
\hline Sub-total (planned culling) & 52 & 6.57 & 74 & 9.36 & 126 & 15.93 \\
\hline \multicolumn{7}{|l|}{ Unplanned sow removal } \\
\hline 1. Reproductive failures & 140 & 17.7 & 67 & 8.47 & 207 & 26.17 \\
\hline No pregnancy & 58 & 7.33 & 27 & 3.41 & 85 & 10.75 \\
\hline Abortion & 32 & 4.05 & 26 & 3.29 & 58 & 7.33 \\
\hline Rebred twice & 29 & 3.67 & 8 & 1.01 & 37 & 4.68 \\
\hline No heat cycle & 11 & 1.39 & 5 & 0.63 & 16 & 2.02 \\
\hline Long dry period & 10 & 1.26 & 1 & 0.13 & 11 & 1.39 \\
\hline 2. Health disorders & 120 & 15.17 & 65 & 8.22 & 185 & 23.39 \\
\hline Vaginal infections & 67 & 8.47 & 31 & 3.92 & 98 & 12.39 \\
\hline Poor appetite & 28 & 3.54 & 14 & 1.77 & 42 & 5.31 \\
\hline Respiratory problems & 23 & 2.91 & 16 & 2.02 & 39 & 4.93 \\
\hline Fever & 2 & 0.25 & 4 & 0.51 & 6 & 0.76 \\
\hline 3. Physical defects & 67 & 8.47 & 54 & 6.83 & 121 & 15.30 \\
\hline Defective & 28 & 3.54 & 33 & 4.17 & 61 & 7.71 \\
\hline Downer sow syndrome & 38 & 4.80 & 19 & 2.40 & 57 & 7.21 \\
\hline Rectal prolapse & 1 & 0.13 & 2 & 0.25 & 3 & 0.38 \\
\hline 4. Leg/foot problems & 53 & 6.70 & 32 & 4.05 & 85 & 10.75 \\
\hline Weak legs & 30 & 3.79 & 16 & 2.02 & 46 & 5.82 \\
\hline Foot rot & 18 & 2.28 & 13 & 1.64 & 31 & 3.92 \\
\hline Splayed legs & 5 & 0.63 & 2 & 0.25 & 7 & 0.88 \\
\hline Flat-footed & 0 & 0.00 & 1 & 0.13 & 1 & 0.13 \\
\hline 5. Mortality & 34 & 4.30 & 33 & 4.17 & 67 & 8.47 \\
\hline Sub-total (unplanned culling) & 414 & 52.34 & 251 & 31.73 & 665 & 84.07 \\
\hline Total culled sows & 466 & 58.91 & 325 & 41.09 & 791 & 100 \\
\hline
\end{tabular}

unplanned sow removals $(\mathrm{p}<0.05)$. The average of LPBA and TPW was highest for planned culling due to old age at 20.2 pigs/year and 17.7 pigs/year, respectively. The highest LPBA (16.0 pigs/year) and TPW (13.8 pigs/year) were observed for unplanned sow removals due to leg/ foot problems. The lowest LPBA (12.0 pigs/year) and TPW (10.6 pigs/year) were found for sows removed due to reproductive failures. The average of LPBA and TPW was significantly higher in the unplanned sow removal of Large White sows (14.8 pigs/year and 12.9 pigs/year) than in Landrace sows (13.5 pigs/year and 12.0 pigs/ year).

\section{DISCUSSION}

\section{Distribution of Culling type and Culling Reasons at Different Parities}

The rate of unplanned sow culling in the local nucleus breeding farm was $84.1 \%$ in total culls, mainly due to reproductive failures $(26.2 \%)$ and health disorders $(23.4 \%)$. By comparison, the rate of unplanned sow culling has reached up to $78.1 \%$ in total culls in commercial farms in Southern China, where reproductive disorders and lameness accounted for $35.3 \%$ and $22.5 \%$, respectively (Zhao et al., 2015).

Reproductive failure is also the commonly cited reason for culling in commercial farms (Sasaki \& Koketsu, 2012). Sow manifesting conditions related to or indicative of reproductive failures, such as the case of anestrus sows and those that fail to show estrus or conceive, are culled because they are accumulating nonproductive days and are likely to have low fertility. Similar findings were also reported in commercial herds with regards to the removal of sows due to reproductive failures declining in later parities (Mote et al., 2009), suggesting that removal for reproduction-related issues maintains a greater role in removals at early parities.

Leg/foot problems are also one of the main causes of early sow removal, as is expected in intensive swine production systems and depending on the type of housing (Cador et al., 2014). In this study, a higher rate of sow culling due to leg/foot problems was found for parity 6 to 10 . This was in agreement with Masaka et al. 
Table 3. Number and distribution of culled sows by breed, culling type, and culling reasons at different parities

\begin{tabular}{|c|c|c|c|c|c|c|c|}
\hline & \multicolumn{6}{|c|}{ Parity at culling } & \multirow{2}{*}{ Total } \\
\hline & 1 & 2 & 3 & 4 & 5 & $6-10$ & \\
\hline \multicolumn{8}{|l|}{ Breeds } \\
\hline Landrace & $122(15.42 \%)$ & $83(10.49 \%)$ & $71(8.98 \%)$ & $46(5.82 \%)$ & $45(5.69 \%)$ & $99(12.52 \%)$ & $466(58.91 \%)$ \\
\hline Large White & $53(6.70 \%)$ & $31(3.92 \%)$ & $40(5.06 \%)$ & $20(2.53 \%)$ & $32(4.05 \%)$ & $149(18.84 \%)$ & $325(41.09 \%)$ \\
\hline \multicolumn{8}{|l|}{ Culling type } \\
\hline Planned sow removal & $12(1.52 \%)$ & $2(0.25 \%)$ & $7(0.88 \%)$ & $3(0.38 \%)$ & $6(0.76 \%)$ & $96(12.14 \%)$ & $126(15.93 \%)$ \\
\hline Unplanned sow removal & $163(20.61 \%)$ & $112(14.16 \%)$ & $104(13.15 \%)$ & $63(7.96 \%)$ & $71(8.98 \%)$ & $152(19.22 \%)$ & $665(84.07 \%)$ \\
\hline \multicolumn{8}{|l|}{ Culling reason } \\
\hline Old age & $0(0.00 \%)$ & $0(0.00 \%)$ & $0(0.00 \%)$ & $0(0.00 \%)$ & $0(0.00 \%)$ & $90(11.38 \%)$ & $90(11.38 \%)$ \\
\hline Poor farrowing performance & $12(1.52 \%)$ & $2(0.25 \%)$ & $7(0.88 \%)$ & $3(0.38 \%)$ & $6(0.76 \%)$ & $6(0.76 \%)$ & $36(4.55 \%)$ \\
\hline Reproductive failures & $58(7.33 \%)$ & $44(5.56 \%)$ & $35(4.42 \%)$ & $16(2.02 \%)$ & $22(2.78 \%)$ & $32(4.05 \%)$ & 207 (26.17) \\
\hline Health disorders & $44(5.56 \%)$ & $29(3.67 \%)$ & $36(4.55 \%)$ & $20(2.53 \%)$ & $14(1.77 \%)$ & $42(5.31 \%)$ & $185(23.39 \%)$ \\
\hline Physical defects & $31(3.92 \%)$ & $17(2.15 \%)$ & $19(2.40 \%)$ & $15(1.90 \%)$ & $16(2.02 \%)$ & $23(2.91 \%)$ & $121(15.30 \%)$ \\
\hline Leg/foot problems & $13(1.64 \%)$ & $11(1.39 \%)$ & $7(0.88 \%)$ & $6(0.76 \%)$ & $11(1.39 \%)$ & $37(4.68 \%)$ & $85(10.75 \%)$ \\
\hline Mortality & $17(2.15 \%)$ & $11(1.39 \%)$ & $7(0.88 \%)$ & $6(0.76 \%)$ & $8(1.01 \%)$ & $18(2.28 \%)$ & $67(8.47 \%)$ \\
\hline Total (Percent) & $175(22.12 \%)$ & $114(14.41 \%)$ & $111(14.03 \%)$ & $66(8.34 \%)$ & $77(9.73 \%)$ & $248(31.35 \%)$ & $791(100.00 \%)$ \\
\hline
\end{tabular}

Note: Numbers in parenthesis are percent of total culls.

Table 4. Sow longevity and lifetime efficiency associated with different culling types and culling reasons in Landrace and Large White sows

\begin{tabular}{|c|c|c|c|c|}
\hline & \multicolumn{2}{|c|}{ Sow longevity } & \multicolumn{2}{|c|}{ Sow lifetime efficiency } \\
\hline & $\begin{array}{l}\text { No. of parity at cull- } \\
\text { ing (PAC) }\end{array}$ & $\begin{array}{l}\text { Productive herd life } \\
\text { (PHL), days }\end{array}$ & $\begin{array}{l}\text { Annualized lifetime } \\
\text { pigs born alive (LPBA) }\end{array}$ & $\begin{array}{c}\text { Annualized total pigs } \\
\text { weaned (TPW) }\end{array}$ \\
\hline Breed & $\mathrm{P}=0.0024$ & $\mathrm{P}=0.0013$ & $\mathrm{P}=0.1354$ & $\mathrm{P}=0.1534$ \\
\hline Landrace & $4.57 \pm 0.16^{\mathrm{b}}$ & $587.6 \pm 26.1^{b}$ & $14.88 \pm 0.42$ & $12.80 \pm 0.40$ \\
\hline Large White & $5.19 \pm 0.14^{\mathrm{a}}$ & $696.0 \pm 23.9^{a}$ & $15.69 \pm 0.39$ & $13.55 \pm 0.38$ \\
\hline Culling type & $\mathrm{P}<0.0001$ & $\mathrm{P}<0.0001$ & $\mathrm{P}<0.0001$ & $\mathrm{P}=0.0113$ \\
\hline Planned sow removal & $5.95 \pm 0.20^{\mathrm{a}}$ & $825.1 \pm 33.8^{\mathrm{a}}$ & $16.47 \pm 0.55^{\mathrm{a}}$ & $13.91 \pm 0.54^{\mathrm{a}}$ \\
\hline Unplanned sow removal & $3.82 \pm 0.09^{\mathrm{b}}$ & $458.5 \pm 14.7^{\mathrm{b}}$ & $14.09 \pm 0.24^{\mathrm{b}}$ & $12.43 \pm 0.23^{\mathrm{b}}$ \\
\hline Culling reasons & $\mathrm{P}<0.0001$ & $\mathrm{P}<0.0001$ & $\mathrm{P}<0.0001$ & $\mathrm{P}<0.0001$ \\
\hline Old age & $8.55 \pm 0.22^{\mathrm{a}}$ & $1267.6 \pm 36.3^{a}$ & $20.16 \pm 0.59^{a}$ & $17.69 \pm 0.56^{\mathrm{a}}$ \\
\hline Poor farrowing performance & $3.36 \pm 0.34^{c}$ & $382.7 \pm 56.7^{\mathrm{cd}}$ & $12.79 \pm 0.93^{\mathrm{d}}$ & $10.14 \pm 0.91^{\mathrm{d}}$ \\
\hline Reproductive failures & $3.26 \pm 0.15^{c}$ & $369.6 \pm 24.1^{\mathrm{d}}$ & $11.95 \pm 0.39^{d}$ & $10.64 \pm 0.37^{\mathrm{d}}$ \\
\hline Health disorders & $3.69 \pm 0.15^{c}$ & $443.5 \pm 25.3^{c}$ & $14.20 \pm 0.41^{\mathrm{c}}$ & $12.27 \pm 0.39^{c}$ \\
\hline Physical defects & $3.62 \pm 0.19^{c}$ & $425.4 \pm 30.9^{\mathrm{cd}}$ & $14.13 \pm 0.50^{c}$ & $12.53 \pm 0.48^{c}$ \\
\hline Leg/foot problems & $4.81 \pm 0.22^{\mathrm{b}}$ & $634.0 \pm 37.0^{\mathrm{b}}$ & $15.99 \pm 0.60^{\mathrm{b}}$ & $13.76 \pm 0.57^{b}$ \\
\hline Mortality & $3.70 \pm 0.25^{c}$ & $419.8 \pm 41.5^{\mathrm{cd}}$ & $14.19 \pm 0.67^{\mathrm{c}}$ & $12.94 \pm 0.65^{\mathrm{bc}}$ \\
\hline Breed $\times$ culling type interaction & $\mathrm{P}=0.0096$ & $\mathrm{P}=0.0168$ & $\mathrm{P}=0.3781$ & $\mathrm{P}=0.8049$ \\
\hline Landrace - Planned & $5.91 \pm 0.30^{\mathrm{a}}$ & $811.2 \pm 48.9^{\mathrm{a}}$ & $16.31 \pm 0.79^{\mathrm{a}}$ & $13.60 \pm 0.76^{\mathrm{a}}$ \\
\hline Landrace - Unplanned & $3.24 \pm 0.11^{\mathrm{c}}$ & $363.9 \pm 18.1^{\mathrm{c}}$ & $13.50 \pm 0.29^{c}$ & $11.99 \pm 0.28^{c}$ \\
\hline Large White - Planned & $6.00 \pm 0.26^{\mathrm{a}}$ & $839.0 \pm 42.4^{\mathrm{a}}$ & $16.64 \pm 0.69^{\mathrm{a}}$ & $14.22 \pm 0.68^{\mathrm{a}}$ \\
\hline Large White - Unplanned & $4.39 \pm 0.13^{b}$ & $553.0 \pm 21.9^{b}$ & $14.74 \pm 0.35^{\mathrm{b}}$ & $12.87 \pm 0.34^{\mathrm{b}}$ \\
\hline Mean \pm SD & $4.11 \pm 2.05$ & $511.8 \pm 339.9$ & $14.28 \pm 5.48$ & $12.55 \pm 5.25$ \\
\hline Coefficient of variation (\%) & 49.99 & 66.41 & 38.4 & 41.88 \\
\hline
\end{tabular}

Note: Least-square means in the same column for each factor with different letter superscripts are significantly different $(\mathrm{p}<0.05)$.

(2014), who reported high frequency in parities greater than 8, and Baglogh et al. (2015), who reported that leg problems were associated with culling due to old age.

The main reason for the planned culling of purebred sows was due to old age, although performed only after the fifth parity. Compared to commercial herds, the primary reason sows over parity 5 were being culled was old age, regardless of their production (Mote et al., 2009). Planned culling due to poor farrowing performance as required by the selection criteria used in the breeding program was not a major cause of sows removal in the nucleus breeding farm. Also, the uneven trend in the low culling rate due to poor farrowing performance with increasing parities may indicate a less strict but more flexible culling strategy.

While culling guidelines were the same for the two breeds, the rate of planned culling was higher in Landrace and Large White sows from parity 1 to 5 but was reversed in favor of Large White sows from parity 6 to 10 . This may indicate that Large White sows were 
culled at later parities. This may also be affected by the variability in the parity and age structure of the pure breeding herds since there were more culled Landrace sows (58.9\%) than Large White sows $(41.1 \%)$ in the data set.

Producers of the nucleus herd should take effective measures to avoid or reduce the incidence of unplanned culling reasons such as (arranged in terms of the proportion of total culls in decreasing order): vaginal infections, no pregnancy, abortion, defective, downer sow syndrome, poor appetite, and respiratory problems for sows at low parity. Producers should also pay attention to mortality and weak legs of sows in later parities.

\section{Sow Longevity and Lifetime Efficiency in Relation to Culling Type and Culling Reasons}

The average PAC for all purebred sows was 4.1, with a high proportion $(22.1 \%)$ of sows culled at parity 1. Not all studies from abroad concurred with the current findings due to differences in sow genotypes, housing conditions, production, and management systems, including culling policies. For example, Engblom et al. (2007) reported an average PAC of 4.4 in culled sows of Swedish commercial herds. In Southern China, the PAC of culled sows in commercial herds was 4.9, with a high proportion of sows (19.6\%) culled at their first parity (Zhao et al., 2015). In both nucleus (this study) and Japanese commercial herds reported by Sasaki \& Koketsu (2012), the unplanned culls had significantly $(p<0.05)$ lower PAC than with planned culls.

In this study, the average PAC, PHL, LPBA, and TPW were 4.6 parities, 588 days, 14.9 pigs/year, and 12.8 pigs/year, respectively for Landrace sows; and 5.2 parities, 696 days, 15.7 pigs/year, and 13.6 pigs/year, respectively for Large White sows. Compared with nucleus breeding farms abroad, Hoge \& Bates (2011) reported a lower average PAC of 3.5 and PHL of 588 days, but higher LPBA of 14.90 pigs/year for Yorkshire sows in the United States. Sobczyńska et al. (2014) also reported a lower average PAC of 3.8 and PHL of 474 days, but TPW of 16.8 in Polish Landrace.

Compared with commercial farms abroad, Sasaki \& Koketsu (2011) reported a similar average PAC of 4.4, lower PHL of 389 days, but higher LPBA of 17.2 pigs/ year in Japan. Ek-Mex et al. (2014) reported a lot higher average LSBA of 22.7 pigs/year and TPW of 21.5 pigs/ year in commercial farms in the subhumid tropics of Mexico. Wang et al. (2019) reported a lower average PAC but higher LPBA of 2.3 parities but a higher LPBA of 18.7 pigs/year in commercial herds in southwest China.

In all reports above, unplanned culling reduced longevity and lifetime efficiency measures in both nucleus and commercial herds.

\section{Improving Sow Longevity and Lifetime Efficiency}

Sows with higher lifetime efficiency were culled (due to old age) at higher parities. Sows with lower lifetime efficiency were culled much earlier due to reproductive failures. However, the PAC or PHL is not the biological cause of sow fertility and lifetime efficiency (Sasaki \& Koketsu, 2008).

On the other hand, improved longevity in sows may result in a greater opportunity to achieve higher lifetime efficiency in commercial breeding farms. Additional benefits from greater sow longevity may include stable health status with fewer low-parity female subpopulations and lower expenses for gilt replacements (Saisaki \& Koketsu, 2011).

Mote et al. (2009) suggested that selection pressure for sow longevity (e.g., sows that can remain in production beyond parity 5) should be placed on sows in the nucleus or seedstock farms of the genetic suppliers would also benefit the reproductive performance of the farm. In this regard, longevity in purebred sows is already included in the breeding objectives of some nucleus farms. Still, it may be improved only through indirect selection in the local breeding program. This is because productive life can be recorded only after a sow had been culled or death occurs.

Information about sow removal that is regularly recorded on-farm should provide insight into the future productivity of purebred sow. The information should also be used in developing better management strategies to avoid unplanned culling, extend the productive life of sows, and hence, improve the production efficiency of the local nucleus breeding farm. Examples of farm strategies that may increase longevity and lifetime efficiency of sows include allowing reserviced sows and multiple mating (Sasaki \& Koketsu, 2008), effective selection of the most fertile gilts for entry to the breeding herd (Patterson \& Foxcroft, 2019), histopathological and macroscopical examinations related to reproductive failures in culled sows (de Jong et al., 2014), reproductive management in different seasons (Segura-Correa et al., 2011 and Masaka et al., 2014), floor cleanliness and wetness, ammonia levels, stocking rate to reduce the risk of leg disorders (Cador et al., 2014), nutrition strategies and cooling systems to reduce heat stress (Zhao et al., 2015), advanced cooling equipment to reduce heat stress (Tani \& Koketsu, 2017), and optimal breeding age of gilts at 233 - 253 days (Malanda et al., 2019).

\section{CONCLUSION}

This study showed that sow removal in a local nucleus breeding farm is largely unplanned (84\%) rather than planned (i.e., due to old age and poor farrowing performance). About half of the reasons for unplanned sow removal were reproductive failures and health disorders, followed (in descending order) by physical defects, leg/foot problems, and mortality. Unplanned culling was associated with lower longevity (i.e., lower parity at culling and productive herd life) and lower lifetime efficiency (i.e., lower lifetime pigs born alive and total pigs weaned). Sows removed for reasons of old age (planned culling) had the highest longevity and lifetime efficiency measures compared with sows culled for other reasons. Sow longevity was higher in Large White than in Landrace. Lifetime efficiency, however, was similar in the two breeds. 


\section{CONFLICT OF INTEREST}

We certify that there is no conflict of interest with any financial, personal, or other relationships with other people or organizations related to the material discussed in the manuscript.

\section{ACKNOWLEDGEMENT}

The authors thank Tony Chua, Jimmy N. Chua, and Marc Anthony dP. Chua of the INFARMCO swine breeding farm in Cabuyao, Laguna, the Philippines, for offering data. Data collection and assistance provided by Adonna Jane C. Rama and Laarnie Mendoza are greatly appreciated.

\section{REFERENCES}

Balogh, P., W. Kapelanski, H. Jankowiak, L. Nagy, S. Kovács, L. Huzsvai, J. Popp, J. Posta, \& A. Soltész. 2015. The productive lifetime of sows on two farms from the aspect of reasons for culling. Ann. Anim. Sci. 5: 747-758. https://doi. org/10.1515/aoas-2015-0020

Cador, C., F. Pol, M. Hamoniaux, V. Dorenlor, E. Eveno, C. Guyomarc'h, \& N. Rose. 2014. Risk factors associated with leg disorders of gestating sows indifferent group-housing systems: A cross-sectional study in108 farrow-to-finish farms in France. Prev. Vet. Med. 116: 102-110. https://doi. org/10.1016/j.prevetmed.2014.05.004

de Jong, E., R. Appeltant, A. Cools, J. Beek, F. Boyen, K. Chiers, \& D. Maes. 2014. Slaughterhouse examination of culled sows in commercial pig herds. Livest. Sci. 167: 362-369. https://doi.org/10.1016/j.livsci.2014.07.001

Ek-Mex, J. E., J. C. Segura-Correa, A. Alzina-López, \& L. Batista-Garcia. 2015. Lifetime and per year productivity of sows in four pig farms in the tropics of Mexico. Trop. Anim. Health Prod. 47: 503-509. https://doi.org/10.1007/ s11250-014-0749-4

Engblom, L., N. Lundeheim, A. M. Dalin, \& K. Andersson. 2007. Sow removal in Swedish commercial herds. Livest. Sci. 106: 76-86. https://doi.org/10.1016/j.livsci.2006.07.002

Hoge, M. D. \& R. O. Bates. 2011. Developmental factors that influence sow longevity. J. Anim. Sci. 89: 238-1245. https:// doi.org/10.2527/jas.2010-3175

Malanda, J., P. Balogh, \& G. Novotni Dankó. 2019. Optimal age of breeding gilts and its impact on lifetime performance. Acta Agraria Debreceniensis 2: 15-20. https://doi. org/10.34101/actaagrar/2/3672
Masaka, L., M. Sungirai, C. Nyamukanza, \& C. Bhondai. 2014. Sow removal in a commercial pig herd in Zimbabwe. Trop. Anim. Health Prod. 46: 725-731. https://doi.org/10.1007/ s11250-014-0554-0

Mote, B. E., J. W. Mabry, K. J. Stalder, \& M. F. Rithschild. 2009. Evaluation of current reasons for removal of sows from commercial farms. Prof. Anim. Sci. 25: 1-7. https://doi. org/10.15232/S1080-7446(15)30672-0

Patterson, J. \& G. Foxcroft. 2019. Gilt management for fertility and longevity. Animals 9: 434. https://doi.org/10.3390/ ani9070434

Sasaki, Y. \& Y. Koketsu. 2008. Sows having high lifetime efficiency and high longevity associated with herd productivity in commercial herds. Livest. Sci. 118: 140-146. https:// doi.org/10.1016/j.livsci.2007.12.029

Sasaki, Y. \& Y. Koketsu. 2011. Reproductive profile and lifetime efficiency of female pigs by culling reason in high-performing commercial breeding herds. J. Swine Health Prod. 19: 284-291. https://www.researchgate.net/ publication/283820442

Sasaki, Y. \& Y. Koketsu. 2012. A herd management survey on culling guidelines and actual culling practices in three herd groups based on reproductive productivity in Japanese commercial swine herds. J. Anim. Sci. 90: 19952002. https://doi.org/10.2527/jas.2011-4313

Segura-Correa, J. C., E. Ek-Mex, A. Alzina-López, \& V. M. Segura-Correa. 2011. Frequency of removal reasons of sows in Southeastern Mexico. Trop. Anim. Health Prod. 43: 1583-1588. https://doi.org/10.1007/s11250-011-9847-8

Sobczyńska, M., T. Blicharski, \& M. Tyra. 2014. A canonical correlation analysis of relationships between growth, compositional traits and longevity, lifetime productivity and efficiency in Polish Landrace sows. Ann. Anim. Sci. 14:257270. https://doi.org/10.2478/aoas-2014-0006

Statistical Analysis System (SAS). 2009. SAS/STAT ® 9.2 User's Guide. $2^{\text {nd }}$ ed. SAS Institute, Inc. Cary, NC USA.

Tani, S. \& Y. Koketsu. 2017. Factors for culling risk due to pregnancy failure in breeding-female pigs. J. Agric. Sci. 9: 109117. https://doi.org/10.5539/jas.v9n1p109

Wang, C., Y. Wu, D. Shu, K. Wei, Y. Zhou, \& J. Peng. 2019. An analysis of culling patterns during the breeding cycle and lifetime production from the aspect of culling reasons for gilts and sows in Southwest China. Animals 9: 160. https:// doi.org/10.3390/ani9040160

Zhao, Y., X. Liu, D. Mo, Q. Chen, \& Y. Chen. 2015. Analysis of reasons for sow culling and seasonal effects on reproductive disorders in Southern China. Anim. Reprod. Sci. 159: 191-197. https://doi.org/10.1016/j.anireprosci.2015.06.018 